\title{
Evaluation of Erythrocyte Sedimentation Rate, C Reactive Protein and Antistreptolysin $O$ Titer regarding Tonsillectomy Indication and their Postoperative Changes
}

\author{
Original \\ Ibrahim A. Abdel-Shafy", Abd El-Latief I. El-Rasheedy", Ayman E. Abu El-Enin*, \\ Article \\ Mohammed S. El-Khouly**, Ahmad M. Hamdan* \\ "Department of Otorhinolaryngology, Faculty of Medicine, Menoufia University, \\ ${ }^{* *}$ Department of Otorhinolaryngology, El-Bagour General Hospital, El-Bagour, Menoufia \\ Egypt.
}

\begin{abstract}
Objective: To evaluate the serum erythrocyte sedimentation rate, $\mathrm{C}$ reactive protein and antistreptolysin $\mathrm{O}$ titer as indicators for tonsillectomy with assessment of their postoperative changes.

Patients and Methods: Our prospective comparative study was carried out on 150 patients divided into two groups. Group I included 75 patients clinically diagnosed as chronic tonsillitis by symptoms and signs and group II included 75 patients with previous tonsillectomy as a control group. Both groups were compared regarding the levels of the three laboratory markers. Also, the preoperative values of these markers were compared with postoperative values at 1, 3 and 6 months.

Results: The values of the three markers in group I were higher than values in group II but statistically insignificant ( $p=0.13,0.11$ and 0.78 respectively). There was a highly significant decrease in postoperative results of erythrocyte sedimentation rate, $\mathrm{C}$ reactive protein in group I at 1, 3 and 6 months after tonsillectomy ( $p$ value $<0.0001$ for all). There was a significant decrease in postoperative results of antistreptolysin O titer in group I at 1,3 and 6 months after tonsillectomy ( $p=0.008,0.019,0.001$ respectively).

Conclusion: Erythrocyte Sedimentation Rate, C Reactive Protein and antistreptolysin O Titer should not be considered as indicators for tonsillectomy in chronic tonsillitis patients by having a non-significant difference when compared with post tonsillectomy patients. Being inflammatory markers, the values of these markers showed a significant decrease after tonsillectomy due to removal of the septic focus of chronic tonsillitis.
\end{abstract}

Key Words: Antistreptolysin O titer, C reactive protein, erythrocyte sedimentation rate, tonsillectomy.

Received: 23 June 2020, Accepted: 31 August 2020

Corresponding Author: Ahmad Mahmoud Hamdan, MD, Department of Otorhinolaryngology, Faculty of Medicine, Menoufia University, Shebin El-Kom, Egypt, Tel.: 00201008993175, E-mail: Ahmed.Hamdan@med.menofia.edu.eg

ISSN: 2090-0740, March 2021 Vol.22, No.1

\section{INTRODUCTION}

Speech Tonsillectomy is the most frequently performed procedure in Otorhinolaryngology, especially in young children. The principal two indications for tonsillectomy include recurrent attacks of tonsillo-pharyngitis and obstructive sleep disordered breathing due to tonsillar hyperplasia. Other indications include peritonsillar abscess, suspicion of malignant disease, speech impairment and halitosis. ${ }^{[1]}$

Group A Beta-hemolytic streptococci are the most common bacterial cause of tonsillitis, with a peak incidence in children aged 5-15 years. Antistreptolysin O (ASO) is the antibody made against streptolysin $\mathrm{O}$ antigen of streptococci. Todd developed a serological assay to detect ASO to become the most antibody response serological test used to confirm antecedent streptococcal infection. ${ }^{[2]}$ It has been considered as one of the first bacterial markers used for diagnosis and follow up of rheumatic fever or scarlet fever which are complications for streptococcal infection. Any increase in ASO titer warns for the possible development of rheumatic fever. ${ }^{[3]}$ Since these antibodies are produced as a delayed antibody reaction to streptococcal bacteria, the presence of these antibodies indicates an exposure to these bacteria. However, as many people are exposed to these bacteria and remain asymptomatic, the mere presence of ASO does not indicate disease. This titer has a significance only if it is greatly elevated $(>200)$, or if a rise in titer can be demonstrated in paired blood samples taken days apart. The antibody levels begin to rise after 1 to 3 weeks of streptococcal Infection, peaks in 3 to 5 weeks and falls back to insignificant levels in 6 months. Values need to be correlated with a clinical diagnosis. ${ }^{[4]}$ 
C-reactive protein (CRP) is a blood test marker for inflammation in the body. CRP is produced in the liver and is classified as an acute phase reactant, which means that its levels will rise in response to inflammation. There are no signs or symptoms that are specific for an elevated C- reactive protein level, because it is not a specific test. Signs or symptoms, if present, would depend on the underlying inflammatory condition that is the cause of the elevated CRP level. ${ }^{[5]}$

The erythrocyte sedimentation rate (ESR) is the rate at which red blood cells sediment in a period of one hour. It is a common hematology test and is a non-specific measure of inflammation. The ESR is increased in inflammation, pregnancy, anemia, autoimmune disorders, infections and some types of cancer. ${ }^{[5]}$ These three laboratory markers are still used by some physicians as markers for chronic tonsillitis and indicators for tonsillectomy and studies are needed to assess such relationship and the effect of tonsillectomy on these markers. The aim of this study was to evaluate the serum ASOT, CRP and ESR as indicators for tonsillectomy and to assess changes after tonsillectomy.

\section{PATIENTS AND METHODS:}

The current study was a cross sectional study with a prospective comparative part conducted at the department of Otorhinolaryngology and Head-Neck surgery Menoufia University and El-Bagour General Hospital after approval of the institutional review board of the faculty. A written consent was taken from every patient before participation in the study.

The study included 150 subjects who were classified as two groups Group I with 75 patients clinically diagnosed as chronic tonsillitis by having recurrent attacks of acute tonsillitis with presence of signs of chronic tonsillitis as hypertrophy of the tonsils, asymmetrical enlargement, enlarged jugulodigastric cervical lymph nodes, pus in the tonsillar crypts and congested anterior pillars. These patients were indicated for tonsillectomy. Group II included 75 patients with matched age and sex with group I who underwent tonsillectomy more than one year ago as a control group.

Exclusion criteria for group I were any patient with bleeding diathesis, cardiac disease, anemia, acute infection, poor anesthetic risk or an uncontrolled medical illness that prevents tonsillectomy. Presence of Jones criteria fulfilling the diagnosis of rheumatic heart disease and rheumatic fever was also a cause for exclusion from the study.

Both groups were subjected to a cross sectional study and tested for the following laboratory markers; CRP tested by latex agglutination method, ASOT tested by ASO latex agglutination and ESR tested by the Westergren method. Reference ranges of ASOT: $0-250 \mathrm{iu} / \mathrm{ml}=$ probably no infection. $250400 \mathrm{iu} / \mathrm{ml}=$ considered equivocal. $>400 \mathrm{iu} /$ $\mathrm{ml}=$ recent infection. In normal persons CRP is usually $<5$ $\mathrm{mg} / \mathrm{L}$ Normal values of ESR. In male 1sthr; 3-5mm. 2ndhr; 6-10mm. In female $1 \mathrm{sthr} ; 8-10 \mathrm{~mm}$. 2ndh; $16-20 \mathrm{~mm}$.

In group I, patients were subjected to tonsillectomy. A written consent was taken from the patients or their parents underwent tonsillectomy. The laboratory markers were estimated one, three and six months after tonsillectomy to be compared with preoperative values.

\section{Outcome measures:}

Primary outcome measure was the evaluation of the difference between both groups regarding these markers. Secondary outcome measure was assessment of the effect of tonsillectomy on the blood level of the three markers.

\section{Statistical Analysis}

After collecting the data, statistical analysis was performed using SPSS software (version 20. IBM, Armonk, NY, USA). Categorical variables were presented as numbers and percentages and were compared using a chi-square test. Data of quantitative variables were presented as mean and standard deviation and turned to be non-normally distributed according to Kolmogorov Smirnov test. Quantitative variables of both groups were compared using Mann Whitney U test. Preoperative and postoperative quantitative data were compared using Wilcoxon Signed Rank test. A p value less than 0.05 was considered statistically significant and $p$ value less than 0.001 was considered highly significant.

\section{RESULTS:}

In the present study, the mean ages of both study groups were 7.17 and 7.84 years respectively with a nonsignificant difference between both groups $(p=0.08)$. There was a non-significant difference between both study groups regarding sex with 35 patients $(46.7 \%)$ of group I and 44 subjects of group II $(58.7 \%)$ being males $(p=0.14)$ (Table 1).

The results of this study showed that the values of ESR, CRP and ASOT in group I were higher than values in group II but statistically insignificant ( $p=0.13,0.11$ and 0.78 respectively) (Table 2).

The findings of this study showed a significant decrease in postoperative values of ESR and CRP in group I at one, three and six months after tonsillectomy when compared with preoperative values $(p$ value $<0.0001$ for all) (Tables 3 and 4). There was a significant decrease in postoperative value of ASOT in group I at one, three and six months after tonsillectomy when compared with preoperative value $(p=0.008,0.019,0.001$ respectively) (Table 5). 
Table 1: Comparison between the two groups regarding epidemiological data:

\begin{tabular}{lccccc}
\hline \multicolumn{1}{l}{ Item } & Group I (75) & Group II (75) & Statistical test & P value \\
\hline Age & & $7.17 \pm 4.41$ & $7.84 \pm 4.04$ & $\mathrm{z}=-1.72714$. & 0.08 \\
Gender & Male & $35(46.7 \%)$ & $44(58.7 \%)$ & Chi $=2.1662$. & 0.14 \\
& Female & $40(53.3 \%)$ & $31(41.3 \%)$ & & \\
\hline
\end{tabular}

z: $\mathrm{z}$ value of Mann Whitney $\mathrm{U}$ test

Chi: Chi square test

Table 2: Comparison between Group II and Group I preoperative levels of ESR, CRP and ASOT:

\begin{tabular}{ccccc}
\hline & Group I Mean \pm SD & Group II Mean \pm SD & Mann Whitney U test & $P$ value \\
\hline ESR & $26.84 \pm 8.75$ & $23.8 \pm 14.18$ & $\mathrm{z}=1.52604$ & 0.13 \\
CRP & $6.49 \pm 2.54$ & $5.93 \pm 2.09$ & $\mathrm{z}=1.61625$ & 0.11 \\
ASOT & $346.67 \pm 229.18$ & $338.67 \pm 265.03$ & $\mathrm{z}=0.27815$ & 0.78 \\
\hline
\end{tabular}

NS $=$ Non-significant $(P$-value $>0.05)$

ESR: Erythrocyte sedimentation rate

CRP: $C$ reactive protein

ASOT: Antistreptolysin O titer

Table 3: Comparison between preoperative and postoperative ESR in group I after 1, 3 and 6 months:

\begin{tabular}{llccc}
\hline Preoperative ESR & \multicolumn{2}{c}{ Postoperative ESR Mean \pm SD } & Wilcoxon signed rank test & $P$-value \\
\hline \multirow{2}{*}{$26.84 \pm 8.75$} & 1 month & $15.55 \pm 7.19$ & $\mathrm{z}=-6.0455$ & $<0.00001^{* *}$ \\
& 3 month & $13.64 \pm 7.05$ & $\mathrm{z}=-6.6978$ & $<0.00001^{* *}$ \\
& 6 month & $10.36 \pm 4.16$ & $\mathrm{z}=-7.2671$ & $<0.00001^{* *}$ \\
\hline
\end{tabular}

**: Highly significant $(P$-value $\leq 0.001)$

ESR: Erythrocyte sedimentation rate

Table 4: Comparison between preoperative and postoperative CRP in group I after 1, 3 and 6 months:

\begin{tabular}{lcccc}
\hline Preoperative CRP Mean \pm SD & Postoperative CRP Mean \pm SD & Wilcoxon signed rank test & $P$-value \\
\hline \multirow{3}{*}{$6.49 \pm 2.54$} & 1 month & $3.2 \pm 1.14$ & $\mathrm{z}=-6.645$ & $<0.00001^{* *}$ \\
& 3 month & $2.72 \pm 1.59$ & $\mathrm{z}=-6.6402$ & $<0.00001^{* *}$ \\
& 6 month & $2.03 \pm 0.93$ & $\mathrm{z}=-7.1514$ & $<0.00001^{* *}$ \\
\hline
\end{tabular}

**: Highly significant $(P$-value $\leq 0.001)$

CRP: C reactive protein

Table 5: Comparison between preoperative and postoperative ASOT in group I after 1, 3 and 6 months:

\begin{tabular}{lcccc}
\hline Preoperative ASOT & \multicolumn{1}{c}{ Postoperative ASOT Mean \pm SD } & Wilcoxon signed rank test & $P$-value \\
\hline \multirow{3}{*}{$346.67 \pm 229.18$} & 1 month & $276 \pm 136.4$ & $\mathrm{z}-2.6666$. & $0.008^{*}$ \\
& 3 month & $269.73 \pm 150.86$ & $\mathrm{z}=-2.3541$. & $0.019^{*}$ \\
& 6 month & $244 \pm 114.183$ & $\mathrm{z}=-3.2512$ & $0.001^{*}$ \\
\hline
\end{tabular}

*: -significant $(P$-value $<0.05)$

ASOT: Antistreptolysin O titer

\section{DISCUSSION}

Results content validity of the sentences through presenting The results of this study showed that the preoperative values of ESR CRP and ASOT in group I patients were higher than values in group II patients but not reaching statistical significance. This can be attributed to the fact that patients included in group I had chronic tonsillitis acting as a septic focus elevating ESR to a greater extent and CRP to lesser extent being acute phase reactants. Also, ASOT was elevated in these patients as streptococci are the main bacterial agents causing tonsillitis and ASO titer remains the most sensitive serological index of Group A betahemolytic streptococcal infection ${ }^{[2]}$. The difference between the two groups did not reach statistical significance excluding these laboratory markers as markers for chronic tonsillitis and indicators for tonsillectomy. This non- significant difference can be attributed to the fact that patients of group II were 
randomly chosen from the outpatient clinic with different acute and chronic inflammatory insults like rhinosinusitis, pharyngitis, laryngitis or otitis media, elevating these markers being inflammatory markers.

The findings of this study showed that preoperative mean ESR, ASOT levels in Group I were $26.8 \mathrm{~mm} / \mathrm{h}$ and 346.7 respectively. These values were less than the findings of Mohamed et al..$^{[5]}$ who found that the pre-intervention mean values of ESR and ASOT were $45.3350 \mathrm{~mm} / \mathrm{h}$ and 522.495 respectively. This can be attributed to different sample size as the number of patients in our study was 75 compared to 200 who underwent tonsillectomy in their study.

Postoperative ESR values in group I patients at 1,3 and 6 months showed a highly significant decrease compared with preoperative value $(p<0.0001$ for all). These findings match the findings of Mohamed et al. ${ }^{[5]}$ who found that the mean ESR readings before management and at 3 and 6 months after tonsillectomy were $45.28,22.36$, and $7.4 \mathrm{ml} / \mathrm{h}$, respectively with a significant difference ( $p=0.0021)$. On the other hand, Badr-El-Din ${ }^{[6]}$ found that ESR levels were normal in 18 patients $(36 \%)$ and high in $32(64 \%), 2$ years after tonsillectomy with a statistically significant difference $(P<0.05)$. This difference in findings can be explained by the long follow up period adopted by Badr-El-Din ${ }^{[6]}$ reaching up to 2 years compared to 6 months in our study. This long follow up period allows any other source of infection to raise the ESR value.

Postoperative CRP values in group I patients at 1 , 3 and 6 months showed a highly significant decrease compared with preoperative value $(p<0.0001$ for all). The significant decrease in ESR and CRP can be explained by the fact that both are elevated in cases of inflammation anywhere in the body whether acute and chronic. Chronic tonsillitis acts as a septic focus causing elevation of these reactants and hence removal of the tonsil would be followed by a significant decrease of their values.

Postoperative ASOT values in group I at 1, 3 and 6 months showed a significant decrease compared with preoperative value $(p=0.008,0.019,0.001$ respectively). Our findings match the findings of other studies having a similar follow up period. Mohamed et $a l^{[5]}$ found that the mean readings of ASOT declined from $518.29 \mathrm{IU} / \mathrm{ml}$ before tonsillectomy to $253.28 \mathrm{IU} /$ $\mathrm{ml}$ after 3 months and then to $117.13 \mathrm{IU} / \mathrm{ml}$ after 6 months after tonsillectomy $(p<0.004)$. Viswanathan et $a l^{[7]}$ found that there was a marked reduction in the ASO titer level from the third month onwards after tonsillectomy and ASO continued to remain negative at six months and one year in a statistically significant level, in $88 \%$ of patients. Bharti et al ${ }^{[8]}$ observed that there was a reduction in ASO titers to levels $<200$ $\mathrm{IU} / \mathrm{ml}$ at 1,2 and 3 months after tonsillectomy with a statistically significant difference ( $p=0.0001$ for all). Kumar and Kumari ${ }^{[9]}$ found that the mean ASOT readings before and 6 months after tonsillectomy were 518.29 and $117.13 \mathrm{IU} / \mathrm{ml}$, respectively with a statistically significant difference $(P$ value $<0.004)$

Our results match the findings of other studies having longer follow up period reaching up to two years. Motta et $a l^{[10]}$ estimated that ASOT levels became normal in $69.8 \%$ of patients, 2 years after tonsillectomy with a statistically significant difference $(P<0.05)$. Also, Badr-El-Din ${ }^{[6]}$ found that ASOT levels were normal in 36 patients $(72 \%)$ and high in $14(28 \%)$; with a statistically significant difference $(P<0.05)$.

The limitations of our study include the relatively small sample size. Larger samples are needed for confirmation of our findings. Also, longer follow up period may be helpful in estimation of longterm changes in these markers. The strength point of our study is the delineation of the non-significant value of these laboratory markers as indicators for tonsillectomy contradicting the practice of some physicians who depend on them for decision making regarding indications of tonsillectomy. The clinical assessment remains the main basis for such decision making.

\section{CONCLUSION}

The laboratory markers of erythrocyte sedimentation rate, $\mathrm{C}$ reactive protein and antistreptolysin $\mathrm{O}$ titer should not be considered as indicators for tonsillectomy in chronic tonsillitis patients by having a non-significant difference when compared with post tonsillectomy patients. Being inflammatory markers, the values of these markers showed a significant decrease after tonsillectomy due to removal of the septic focus of chronic tonsillitis.

\section{CONFLICT OF INTEREST}

There are no conflicts of interest.

\section{REFERENCES}

1. Baugh RF, Archer SM, Mitchell RB, Rosenfeld RM, Amin R, Burns JJ, et al. Clinical practice guideline: tonsillectomy in children. Otolaryngol Head Neck Surg. 2011; 144: S1-30.

2. Hammouda M, Abdel-Khalek Z, Awad S, AbdelAziz M, Fathy M. Chronic tonsillitis bacteriology in Egyptian children including antimicrobial susceptibility. Australian Journal of Basic and Applied Sciences. 2009; 3(3): 1948-53. 
3. Nordet P, Lopez R, Sarmiento L, Nordet P, Dueñas A. Prevention and control of rheumatic fever and rheumatic heart disease: the Cuban experience (1986-1996-2002). Cardiovascular journal of Africa. 2008; 19(3):135

4. Brook I, Gober AE. Increased recovery of Moraxella catarrhalis and Haemophilus influenzae in association with group A $\beta$-haemolytic streptococci in healthy children and those with pharyngo-tonsillitis. Journal of medical microbiology. 2006; 55(8):989-92.

5. Mohamed A, El Tabbakh M, Zeitoun A, El Hennawi D. Acute-phase reactants in children with recurrent tonsillitis treatedby tonsillectomy versus long- acting penicillin. Egypt J Otolaryngol. 2013; 29:99-103.

6. Badr-El-Din MM. Evaluation of some serum acute phase reactants and antistreptolysin $\mathrm{O}$ titer in streptococcal and non streptococcal chronic tonsillitis:cross section descriptive study. Univ Alex Lib. 1988; 73-80.
7. Viswanathan N, Nair SK, Thulseedharan S, Effect of tonsillectomy on aso-titer. Indian J Otolaryngol Head and Neck Surg. 2000;52(4): 329-331.

8. Bharti P, Mohindroo S, Mohindroo NK, Sharma D, Kanga A. Tonsillectomy and its effect on ASO titer. Int J Res Med Sci. 2017; 5:2385-9.

9. Kumar A, Kumari N. Evaluate the effectiveness of tonsillectomy and long-acting penicillin on the levels of the antistreptolysin $\mathrm{O}$ titer in children with recurrent tonsillitis. Int J Res Med Sci. 2019 7(5):1692-1695

10. Motta G, Esposito E, Motta S, Mansi N, Cappello V, Cassiano B, et al. The treatment of acute recurrent pharyngotonsillitis. Acta Otorhinolaryngol. Ital 2006; 26(84): 5-29. 